\title{
Efficacy of ampicillin trihydrate or ceftiofur hydrochloride for treatment of metritis and subsequent fertility in dairy cows
}

\author{
F. S. Lima, ${ }^{*}$ A. Vieira-Neto,† G. S. F. M. Vasconcellos, ${ }^{*}$ R. D. Mingoti, ${ }^{*}$ E. Karakaya, ${ }^{* 1}$ E. Solé, ${ }^{*}$ R. S. Bisinotto, ${ }^{*}$ \\ N. Martinez, ${ }^{*}$ C. A. Risco,† K. N. Galvão,† and J. E. P. Santos*² \\ *Department of Animal Sciences, and \\ †Department of Large Animal Clinical Sciences, University of Florida, Gainesville 32611-0910
}

\section{ABSTRACT}

Our objectives were to evaluate the efficacy of ampicillin trihydrate for the treatment of metritis in dairy cows compared with ceftiofur hydrochloride and the subsequent effects on pregnancy at first insemination (P/AI). Cows in the first $12 \mathrm{~d}$ in milk (DIM) with a uterine discharge score of 5 (watery, reddish or brownish discharge of foul smell) and rectal temperature $<39.5^{\circ} \mathrm{C}$ were diagnosed with metritis based on the fetid discharge, and cows with metritis and rectal temperature $\geq 39.5^{\circ} \mathrm{C}$ were diagnosed as having puerperal metritis. Cows with metritis $(\mathrm{n}=528)$ were blocked by parity and type of metritis as fetid discharge or puerperal metritis and, within each block, assigned randomly to receive $11 \mathrm{mg} / \mathrm{kg}$ of ampicillin $(\mathrm{n}=259)$ or $2.2 \mathrm{mg} /$ $\mathrm{kg}$ of ceftiofur $(\mathrm{n}=269)$ once daily for $5 \mathrm{~d}$. Day of diagnosis of metritis was considered study d 1 . A cohort of 268 cows without metritis was selected randomly at 12 DIM. Rectal temperature was measured in cows with metritis on study d 1 to 7 , and 12 , and vaginal discharge was scored on study d 5, 7, and 12. Metritis cure was characterized by vaginal discharge score of $<5$ or by vaginal discharge score of $<5$ and no fever. At 32 \pm 3 DIM, vaginal discharge was scored for diagnosis of purulent vaginal discharge. At $39 \pm 3$ DIM, endometrial cytology was performed. At $53 \pm 3$ and $67 \pm 3$ DIM, ovaries were scanned to determine estrous cyclicity. Pregnancy was evaluated after the first AI. Cure of metritis based on vaginal discharge $<5$ was greater for ampicillin than ceftiofur on $\mathrm{d} 5(37.1$ vs. $25.2 \%)$ and 7 ( 57.2 vs. $46.3 \%)$, but not on d $12(82.0$ vs. $85.0 \%)$. Cure of metritis based on vaginal discharge $<5$ and no fever was greater for ampicillin than for ceftiofur only on $\mathrm{d}$ 7 (50.4 vs. $37.9 \%)$, but not on 5 (23.1 vs. $17.6 \%)$ and 12 (66.1 vs. $67.4 \%$ ). Cows with puerperal metritis had

\footnotetext{
Received October 6, 2013.

Accepted May 13, 2014.

${ }^{1}$ Current address: Department of Obstetrics and Gynecology, Faculty of Veterinary Medicine, Uludag University, Görükle Kampüs, Bursa, Turkey 16059.

${ }^{2}$ Corresponding author: jepsantos@ufl.edu
}

reduced cure compared with cows with fetid discharge on $\mathrm{d} 5$ (30.5 vs. $12.8 \%), 7$ (55.2 vs. $33.6 \%$ ), and 12 (72.0 vs. $61.1 \%$ ). The proportion of cows with fever on any day after therapy started did not differ between treatments. Fifty-three percent of cows with metritis based on fetid discharge developed fever after initiating antimicrobial therapy. Cows receiving ampicillin had less prevalence of purulent vaginal discharge than those treated with ceftiofur ( 57.7 vs. $67.8 \%$ ), but they were both greater than cows without metritis (21.9\%). Prevalence of cytological endometritis did not differ between ampicillin and ceftiofur (30.0 vs. $25.4 \%$ ), but they were both greater than cows without metritis (14.5\%). The proportion of estrous cyclic cows (75.0\%) and $\mathrm{P} / \mathrm{AI}$ did not differ among treatments (ampicillin $=28.0 \%$ vs. ceftiofur $=28.3 \%$ vs. without metritis $=$ $30.5 \%$ ). Clinical cure was faster for ampicillin than for ceftiofur, but on study d 12 both treatments resulted in similar cure. Clinical cure was less for cows with puerperal metritis than for cows with fetid uterine discharge. Despite differences in uterine health, $\mathrm{P} / \mathrm{AI}$ at the first insemination did not differ among treatments. Key words: ampicillin, ceftiofur, metritis, pregnancy

\section{INTRODUCTION}

Metritis is a prevalent uterine disease that affects early postpartum dairy cows characterized by an abnormally enlarged uterus and a fetid, watery red-brown fluid to viscous off-white purulent uterine discharge that can be accompanied or not by fever within the first 21 d postpartum (Sheldon et al., 2006). The incidence of metritis in dairy cows ranges from 10 to 36\% (Goshen and Shpigel, 2006; Santos et al., 2010; Chapinal et al., 2011) and is more frequently diagnosed during the first week postpartum (Sheldon et al., 2006).

The economic losses caused by metritis are striking calculated at $\$ 380$ per affected cow, and the losses are caused by reduced milk production, delayed pregnancy, treatment, and increased culling and death (Drillich et al., 2001). Additionally, cows diagnosed with metritis have an increased risk to develop both clinical and cy- 
tological endometritis (Galvão et al., 2009; Martinez et al., 2012). The main bacteria isolated from cases of uterine infection include Escherichia coli, Trueperella (formerly Arcanobacterium) pyogenes, and anaerobic bacteria such as Prevotella (formerly Bacteroides) species and Fusobacterium necrophorum (Griffin et al., 1974; Noakes et al., 1989; Sheldon et al., 2002). Thus, it is reasonable to suggest that the use of antimicrobials with broad spectrum activity against these uteropathogenic bacteria is the preferred choice for therapy of metritis.

Ampicillin is a $\beta$-lactam antibiotic that binds to specific penicillin-binding proteins in the inner surface of the bacterial cell wall acting as an irreversible inhibitor of dd-transpeptidase, an essential enzyme that bacteria use to synthesize peptidoglycan and other components of the cell wall (Prescott and Baggott, 1993; Chambers, 2007). Disruption in cell wall synthesis ultimately leads to cell lysis and death of the bacteria. The amino group in the chemical composition of ampicillin is thought to facilitate binding and penetration into the outer membrane of gram-negative bacteria, thereby increasing the spectrum of action when compared with penicillin. Ampicillin received approval in 1998 for use in dairy cattle in the United States (Center for Veterinary Medicine, Food and Drug Administration new animal drug application 200-180; FDA, 1998) and it is indicated for therapy of infections caused by E. coli (Burrows et al., 1993; Lehtolainen et al., 2003), but it is also efficacious against other gram-negative bacteria and those associated with metritis (Simon, 1977; Malinowski et al., 2011).

Most bacteria associated with metritis are susceptible to ceftiofur (Malinowski et al., 2011), and administration of ceftiofur hydrochloride has been shown to be an efficacious therapy for puerperal metritis in dairy cows (Chenault et al., 2004). Although ceftiofur is unique in that amounts of residue appearing in milk are below the tolerance for human consumption, so no withholding is required when used as indicated in the label, 23 to $35 \%$ of the cows treated with ceftiofur hydrochloride had failure to cure metritis (Chenault et al., 2004). Additionally, because ceftiofur is the only third-generation cephalosporin labeled in the United States to treat metritis, pneumonia, necrotizing pododermatitis, and mastitis, it might lead to selection pressure, which has been suggested to be involved with emergence and dissemination of $\beta$-lactamase CMY-2, a major mechanism of third-generation cephalosporin resistance (Jiang et al., 2006; Tragesser et al. 2006). Thus, an alternative treatment for metritis that either improves cure rates or offers an escape therapy for cows that failed to cure metritis is warranted. Moreover, having alternative therapies for metritis can potentially mitigate the se- lection pressure caused by widespread use of ceftiofur. To date, no published study has evaluated efficacy of systemic administration of ampicillin for treatment of metritis in dairy cows.

We hypothesized that ampicillin would be an effective therapy for metritis, resulting in similar clinical cure and subsequent reproductive performance compared with cows treated with ceftiofur, a common antibiotic labeled and prescribed for treatment of metritis in the United States. The objectives of the present study were to evaluate the efficacy of ampicillin trihydrate for treatment of metritis in dairy cows compared with ceftiofur hydrochloride and subsequent effect on pregnancy to the first postpartum AI (P/AI).

\section{MATERIALS AND METHODS}

The University of Florida Institute of Food and Agricultural Sciences Animal Research Committee approved all procedures involving animals in the current study.

\section{Cows, Housing, and Diets}

The present study was conducted on a single dairy farm located in central Florida. The lactating herd was composed of approximately 5,270 lactating cows during the study period with a yearly rolling herd average milk yield of approximately $11,000 \mathrm{~kg}$. A total of 528 cows diagnosed with metritis (264 primiparous and 264 multiparous) were enrolled in the study from October 10, 2012, to January 5, 2013. Those cows represent all cows diagnosed with metritis in the dairy during the enrollment period. Additionally, 268 herdmates (134 primiparous and 134 multiparous) without metritis were enrolled on d 12 postpartum. The cows without metritis were selected randomly and retrospectively based on the same day of calving and parity to match herdmates diagnosed with metritis.

Cows were housed in freestall barns with sand-bedded stalls and equipped with sprinklers and fans for forced evaporative cooling. The study was conducted when environmental temperature and humidity were not conducive of heat stress in dairy cows and unlikely to have altered body temperature measurements. The temperature and relative humidity data were obtained from the Florida Automated Weather Network (http:// fawn.ifas.ufl.edu) from October 2012 to January 2013, approximately $40 \mathrm{~km}$ from the experimental location. Average daily temperature-humidity index (THI) was calculated as THI $=$ temperature $\left({ }^{\circ} \mathrm{F}\right)-[0.55-(0.55$ $\times$ relative humidity $)] \times($ temperature -58$)$. The mean daily THI averaged $65.6,61.4,58.7$, and 60.1 for the months of October 2012 to January of 2013. 
Cows received the same TMR to meet or exceed the nutrient requirements for a lactating Holstein cow producing $45 \mathrm{~kg} / \mathrm{d}$ of milk with $3.5 \%$ fat and $3.2 \%$ true protein when DMI is $25 \mathrm{~kg} / \mathrm{d}$ (NRC, 2001). Diets consisted of ryegrass silage, corn silage, wet brewer's grains, dried distillers grains, earlage, ground corn, citrus pulp, solvent-extracted soybean meal, expeller soybean meal, corn gluten feed, molasses, minerals, and vitamins. The estimated nutrient content of the ration was 1.66 Mcal of net energy, $16.5 \% \mathrm{CP}, 31.1 \% \mathrm{NDF}$, $26.4 \%$ starch, and $4.1 \%$ FA.

\section{Case Definition}

A vaginal discharge scoring system based on Sheldon et al. (2006) was used with the following definitions: 1 $=$ clear or translucent mucus; $2=$ mucus containing flecks of white or off-white pus; $3=$ discharge containing $\leq 50 \%$ white or off-white mucopurulent material; 4 $=$ discharge containing $>50 \%$ purulent material; and $5=$ watery, reddish or brownish color of foul smell. Metritis was defined as a cow with a vaginal discharge score of 5 (Sheldon et al., 2006). Cows with metritis and concurrent rectal temperature $\geq 39.5^{\circ} \mathrm{C}$ were diagnosed as puerperal metritis (Chenault et al., 2004; McLaughlin et al., 2012).

\section{Diagnosis of Metritis, Treatment Allocation, and BCS}

Rectal temperature was measured daily using an electronic thermometer (GLA Agricultural Products, San Luis Obispo, CA) immediately after the morning milking, starting at approximately $0600 \mathrm{~h}$ and finishing at around $0730 \mathrm{~h}$. The calibration of the thermometer was checked daily by removing the probe as indicated by the manufacturer. The probe of the thermometer was introduced entirely in into the rectum of each cow and slightly pressed against the mucosa until the temperature stabilized to be recorded. Cows with a rectal temperature $\geq 39.5^{\circ} \mathrm{C}$ were considered febrile. Vaginal discharge retrieved using the Metricheck device (Simcro, Hamilton, New Zealand) was scored at 4, 6, and 8 DIM and on any day that a cow had fever. Cows were then classified on the day of diagnosis based on the type of metritis as fetid uterine discharge (watery, reddish or brownish discharge of foul smell, and rectal temperature $<39.5^{\circ} \mathrm{C}$ ) or puerperal metritis (watery, reddish or brownish discharge of foul smell, and rectal temperature $\geq 39.5^{\circ} \mathrm{C}$ ).

Pre-prepared randomization forms were designed for cows with fetid discharge or cows with puerperal metritis. Each of the forms was prepared for primiparous and for multiparous separately, and each contained blocks of 3 cows, 1 to receive ampicillin, 1 to receive ceftiofur, and 1 for a cow without metritis. Treatments were allocated randomly within block and randomization of cows was based on sequence of diagnosis of metritis, such that cows with metritis $(\mathrm{n}=528)$ were blocked by parity (primiparous or multiparous) and type of metritis $($ fetid discharge $=312$ or puerperal metritis $=216$ ) and, within each block, assigned randomly to receive 11 $\mathrm{mg}$ of ampicillin $/ \mathrm{kg}$ of BW i.m. $(\mathrm{n}=259)$ as ampicillin trihydrate (Polyflex, Boehringer Ingelheim Vetmedica, St. Joseph, MO) or $2.2 \mathrm{mg}$ of ceftiofur $/ \mathrm{kg}$ of BW i.m. $(\mathrm{n}=269)$ as ceftiofur hydrochloride (Excenel RTU sterile suspension, $50 \mathrm{mg} / \mathrm{mL}$ of ceftiofur as hydrochloride salt, Zoetis, Madison, NJ) once daily for $5 \mathrm{~d}$ according to Food and Drug Administration label approval in the United States. The product containing ampicillin was diluted with $80 \mathrm{~mL}$ of sterile distilled water such that for both antibiotics the dose administered was $1 \mathrm{~mL} / 22.5 \mathrm{~kg}$ of BW. Polyflex is approved for use in lactating dairy cattle but not labeled for treatment of metritis in the United States, although it can be used as such in an extra-label manner under the supervision of the herd veterinarian.

The day of diagnosis of metritis was considered study d 1 and it was also the first day of treatment. A cohort of 268 cows without metritis was selected randomly and retrospectively at 12 DIM based on the same day of calving and same parity to match herdmates diagnosed with metritis. The body condition of all cows was assessed at enrollment in the study using a scoring system from 1 (emaciated) to 5 (obese) according to Ferguson et al. (1994) as depicted in the Elanco BCS chart (Elanco Animal Health, 2009). Cows that had dystocia based on any type of assistance during delivery, a stillbirth calf, twin calves, or occurrence of retained fetal membranes were classified as having calving-related disorders.

\section{Rectal Temperatures, Vaginal Discharge Evaluation, and Cure Definitions}

Cows diagnosed with metritis had rectal temperature recorded from study d 1 to 7 , and again on study d 12, immediately after the morning milking between 0600 and $0800 \mathrm{~h}$ (Figure 1). Additionally, all cows had vaginal discharge scored using the same 1 to 5 scoring system again on study d 5, 7, and 12 . Metritis cure was defined according to 3 different clinical responses, based on vaginal discharge only, combination of vaginal discharge and rectal temperature, and finally whether or not another additional antimicrobial therapy was administered during the 12 -d study observation period. Cows with mastitis during the 12 -d evaluation period for cure of metritis received additional antimicrobial therapy via intramammary treatment. Cows that had 
Day in the study Day postpartum

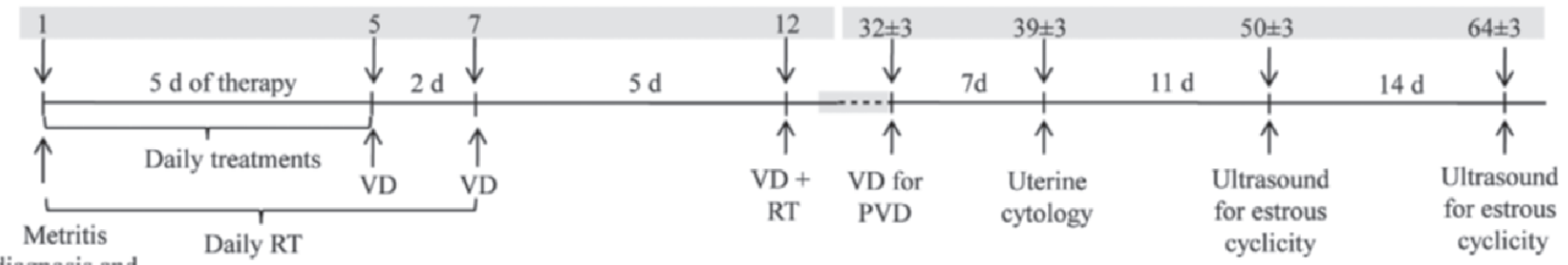

diagnosis and

enrollment

Figure 1. Diagram of treatments for metritis, monitoring of cure, and evaluation of uterine health. Cows diagnosed with metritis were blocked by parity and type of metritis (fetid discharge vs. puerperal metritis) and, within each block, assigned randomly to receive $11 \mathrm{mg} / \mathrm{kg}$ of ampicillin or $2.2 \mathrm{mg} / \mathrm{kg}$ of ceftiofur once daily for $5 \mathrm{~d}$. Metritis based on fetid discharge was defined as vaginal discharge (VD) that was watery, reddish or brownish in color, foul smelling (VD score $=5$ ), and with a rectal temperature $(\mathrm{RT})<39.5^{\circ} \mathrm{C}$. Puerperal metritis was defined as a VD score of 5 and $\mathrm{RT} \geq 39.5^{\circ} \mathrm{C}$. PVD = purulent vaginal discharge. Day of diagnosis of metritis was considered study d 1 .

no cure of metritis by d 5 or that developed pneumonia or digital dermatitis after the end of the 5-d therapy for metritis received additional antimicrobial therapy.

Initially, cure was determined based solely on a vaginal discharge score $<5$, which implied absence of a fetid watery discharge of reddish or brownish color on study d 5, 7, and 12. A second definition for clinical cure was based on vaginal discharge $<5$ and a rectal temperature $<39.5^{\circ} \mathrm{C}$. Finally, cure on d 12 of the study was also determined based on vaginal discharge score $<5$, rectal temperature $<39.5^{\circ} \mathrm{C}$, and no additional health problem or antimicrobial administered before d 12 of the study. The proportion of cows with fever (rectal temperature $\geq 39.5^{\circ} \mathrm{C}$ ) on a given day between $\mathrm{d} 2$ and 12 was also evaluated.

\section{Evaluation of Purulent Vaginal Discharge, Cytological Endometritis, and Estrous Cyclicity}

Vaginal discharge was collected from all metritic cows and cows without metritis enrolled in the study at $32 \pm 3$ DIM using the Metricheck device. Vaginal discharge was scored according to Sheldon et al. (2006) and cows were classified as having purulent vaginal discharge (PVD) if the vaginal discharge score was $>2$, according to the criterion suggested by Dubuc et al. (2010). Endometrial tissue was sampled from all cows in the study for cytological examination on d $39 \pm 3$ postpartum using the cytobrush technique (Lima et al., 2013) using a stainless steel gun protected by a oneway plastic tube protector (Continental Plastics Corp., Delavan, WI). After sample collection, the cytobrush was rolled onto a slide and air-dried immediately. The slides were transported to the laboratory and stained using diff-quick stain kit (IMEB, San Marcos, CA). Technicians blinded to treatments read the slides. Two hundred cells were counted in each slide using a microscope at $400 \times$ magnification to determine the proportion of PMNL relative to the total leukocytes and endometrial cells counted. Cows with a proportion of PMNL $\geq 5 \%$ were classified as having cytological endometritis, also known as subclinical endometritis (Gilbert et al., 2005).

Estrous cyclicity was evaluated at $50 \pm 3$ and $64 \pm$ 3 DIM by ultrasonographic examination of the ovaries using a portable ultrasound scanner equipped with a 7.5-MHz transrectal probe (Easi-Scan, BCF Technology, Rochester, MN). Cows with a corpus luteum with diameter $>15 \mathrm{~mm}$ recorded on 1 of the 2 examination days were considered to be estrous cyclic, whereas those without a visible corpus luteum $>15 \mathrm{~mm}$ in both examinations were considered anovular. The cut-off diameter of $15 \mathrm{~mm}$ was selected based on the highest sensitivity to detect a cows with a corpus luteum with progesterone $>1 \mathrm{ng} / \mathrm{mL}$ (Bicalho et al., 2008).

\section{Reproductive Management for First Postpartum AI}

Cows enrolled in the present study were subjected to a reproductive program for synchronization of estrus and ovulation (Figure 2). Cows received an i.m. injection of $25 \mathrm{mg}$ of $\mathrm{PGF}_{2 \alpha}(5 \mathrm{~mL}$ of Lutalyse, $5 \mathrm{mg} / \mathrm{mL}$ of dinoprost as tromethamine salt; Zoetis) administered on $\mathrm{d} 50 \pm 3$ and $64 \pm 3$ postpartum. At the second injection of $\mathrm{PGF}_{2 \alpha}$, cows' tailheads were painted daily with chalk and those identified in estrus by removal of tail chalk received AI on the same morning. Cows not observed in estrus within $12 \mathrm{~d}$ of the second $\mathrm{PGF}_{2 \alpha}$ treatment were enrolled in the 5 -d timed AI program at $76 \pm 3$ DIM (Figure 2). The protocol included an i.m. injection of $86 \mu \mathrm{g}$ of $\mathrm{GnRH}(2 \mathrm{~mL}$ of Cystorelin sterile solution, gonadorelin diacetate tetrahydrate equivalent to $43 \mu \mathrm{g}$ of gonadorelin/mL; Merial Ltd., Duluth, GA) followed by an i.m. injection of $\mathrm{PGF}_{2 \alpha}$ on $\mathrm{d} 5$ and another on d 6 of the protocol. A second i.m. injection of GnRH was administered concurrently with AI at 72 
$\mathrm{h}$ after the first $\mathrm{PGF}_{2 \alpha}$. Pregnancy was diagnosed by transrectal ultrasonography on d $34 \pm 3$ after AI. The presence of an amniotic vesicle containing an embryo with a heartbeat was used as the criteria to determine pregnancy. Pregnant cows on d $34 \pm 3$ were reexamined for pregnancy by transrectal palpation 4 wk later, on d 62 of gestation. Pregnancy per AI was calculated by dividing the number of cows diagnosed pregnant at $d$ 34 or 62 after AI by the number of cows receiving AI. Pregnancy loss was calculated as the number of cows that lost a pregnancy between d 34 and 62 after AI divided by the number of cows diagnosed pregnant on d 34 after AI. Cows that were detected in estrus before study d 32 were reinseminated and considered nonpregnant. Inseminations were performed by 6 technicians with semen from 13 Holstein sires.

\section{Statistical Analysis}

A noninferiority efficacy of ampicillin to cure metritis was expected and accepted if no more than 6 to 8 percentage units of numerical difference in cure between treatments was observed at the evaluation times. We based our assumption for noninferiority on data of Chenault et al. (2004), which described cure of cows with puerperal metritis after therapy with ceftiofur. Therefore, the sample size was calculated assuming that $41 \%$ and $77 \%$ of the cows treated with ceftiofur would experience clinical cure on d 7 and 14, respectively, after initiation of treatments. The sample size was calculated using the Power and Sample Size Calculator of Minitab (ver. 16.2.4; Minitab Inc. State College, PA). Using $\alpha=0.05$ and $\beta=0.20$, a 9 percentage units difference in cure on d 7 (e.g., 41 vs. 32 or $50 \%$ ), or 7 percentage units difference in cure on d 12 (77 vs. 69 or
$84 \%$ ) would be needed to detect differences in efficacy between treatments. Therefore, we anticipated similar efficacy in clinical cures for ampicillin when they were between 33 and $49 \%$ on $\mathrm{d} 7$ and between 70 and $83 \%$ on d 12 .

Categorical data were analyzed by logistic regression using the GLIMMIX procedure of SAS version 9.3 (SAS/STAT, SAS Institute Inc., Cary, NC) fitting a binary distribution. Treatment was forced in the final models, but the interaction between treatment and covariates were sequentially removed from the models if $P>0.10$. The models for cure of metritis included the fixed effects of treatment (ampicillin vs. ceftiofur), type of metritis (fetid discharge vs. puerperal metritis), parity (primiparous vs. multiparous), calving-related disorders (yes or no), BCS, and interactions between treatment and parity, treatment and type of metritis, and treatment and calving-related disorders, and the random effect of block. Two models were built for analysis of PVD, cytological endometritis, and estrous cyclic status. The first model included only cows randomly assigned to treatments and excluded cows without metritis, and the statistical models were identical to those described for cure of metritis. The second model evaluated all cows, including cows without metritis, and type of metritis was removed from the explanatory variables. The models for $\mathrm{P} / \mathrm{AI}$ and pregnancy loss were similar to those used to analyze PVD, but also included type of insemination (after detected estrus or timed AI), technician, and sire.

The continuous data with repeated measures over time within an experimental unit were analyzed using the GLIMMIX procedure of SAS (SAS/STAT version 9.3; SAS Institute Inc., Cary, NC) with models fitting a Gaussian distribution. Data were tested for normality

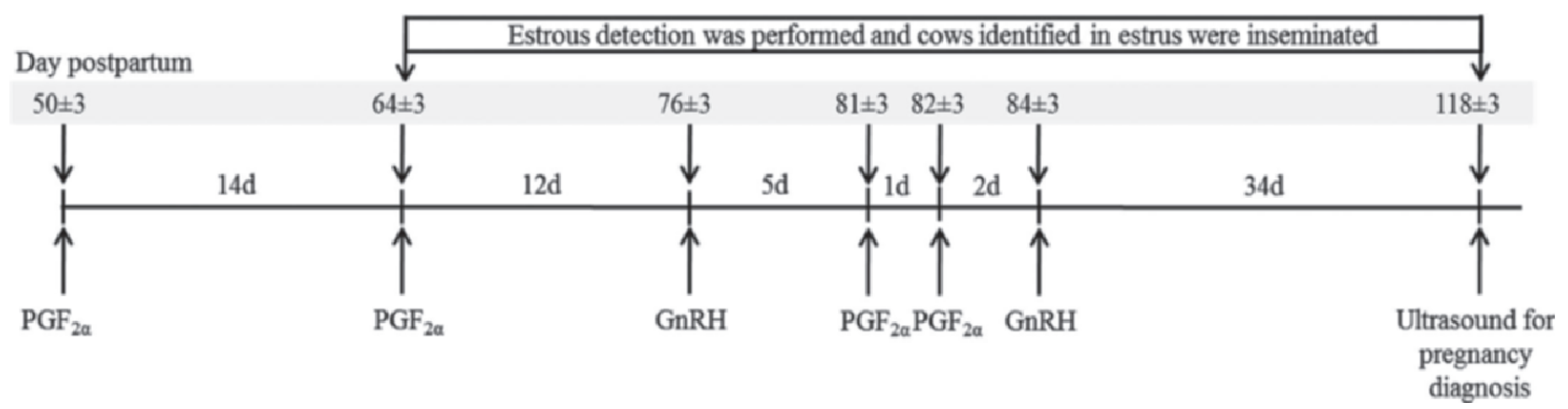

Figure 2. Diagram of the reproductive program used for first insemination and pregnancy diagnosis. Cows diagnosed with metritis were blocked by parity and type of metritis (fetid discharge vs. puerperal metritis) and, within each block, assigned randomly to receive $11 \mathrm{mg} / \mathrm{kg}$ of ampicillin or $2.2 \mathrm{mg} / \mathrm{kg}$ of ceftiofur once daily for $5 \mathrm{~d}$. Metritis based on fetid discharge was defined as vaginal discharge (VD) that was watery, reddish or brownish in color, foul smelling (VD score $=5$ ), and with a rectal temperature $(\mathrm{RT})<39.5^{\circ} \mathrm{C}$. Puerperal metritis was defined as a VD score of 5 and $\mathrm{RT} \geq 39.5^{\circ} \mathrm{C}$. Cows treated for metritis and a cohort of herdmates without metritis were subjected to a presynchronized 5 -d timed-AI program. Cows observed in estrus any time after the second $\mathrm{PGF}_{2 \alpha}$ injection at $64 \pm 3 \mathrm{~d}$ postpartum were inseminated. 
of residuals, and non-normally distributed data were transformed before analysis if improvement in residual distribution was observed. Rectal temperature was analyzed with the fixed effect of treatments (ampicillin vs. ceftiofur), type of metritis (fetid discharge vs. puerperal metritis), parity, the interactions between treatment and type of metritis, treatment and parity, parity and type of metritis, and treatment and type of metritis and parity. Block and cow nested within treatment were the random terms in the models. The covariance structure that resulted in the smallest Akaike's information criterion was selected for the model. Differences with $P \leq$ 0.05 were considered significant and those with $0.05<$ $P \leq 0.10$ were considered tendencies.

\section{RESULTS}

The prevalence of metritis in the farm throughout the study period was $36.1 \%(528 / 1,463)$. Of the 528 cows enrolled in the study, $40.9 \%$ were considered to have puerperal metritis on the day of diagnosis (216/528), resulting in an overall incidence of puerperal metritis of $14.8 \%(216 / 1,463)$.

\section{Rectal Temperatures and Proportion of Cows with Fever After Treatments}

On the day of study enrollment, the rectal temperature was greater $(P<0.05)$ for ampicillin than ceftiofur $\left(39.41 \pm 0.02\right.$ vs. $\left.39.35 \pm 0.02^{\circ} \mathrm{C}\right)$, and this difference was observed only in cows with puerperal metritis (Figure 3). Nevertheless, the mean rectal temperature of cows after treatments were initiated did not differ between treatments (Figure 3). An interaction $(P<$ 0.001 ) between treatment and day in the study was observed for rectal temperature because cows receiving ceftiofur had lower temperatures in the first few days of treatment, whereas cows receiving ampicillin had lower temperatures on d 6 and 7 after start of treatment (Figure 3). As anticipated, type of metritis influenced $(P<$ 0.001 ) rectal temperature, and it was greater for cows with puerperal metritis than those with fetid discharge. On d 2 of treatment, cows with fetid discharge had a slight elevation in rectal temperature (Figure 3A), whereas those with puerperal metritis experienced a marked decline in rectal temperature (Figure 3B).

The proportion of cows with fever after antimicrobial therapy was initiated did not differ between treatments and averaged $20.2 \%$ throughout the 12 -d posttreatment evaluation. Interestingly, $53.2 \%$ of cows diagnosed with metritis based only on fetid discharge eventually developed at least $1 \mathrm{~d}$ of fever after antimicrobial therapy had initiated. In cows with metritis based on fetid uterine discharge, the incidence of fever after antimicrobial therapy was initiated did not differ $(P=0.80)$ between treatments and it was $54.0 \%$ for ampicillin and $52.5 \%$ for ceftiofur. The proportion of cows with fever on any given day after treatments were initiated was greater $(P<0.001)$ for cows with puerperal metritis compared with those with fetid discharge (30.6 vs. 12.7\%). The
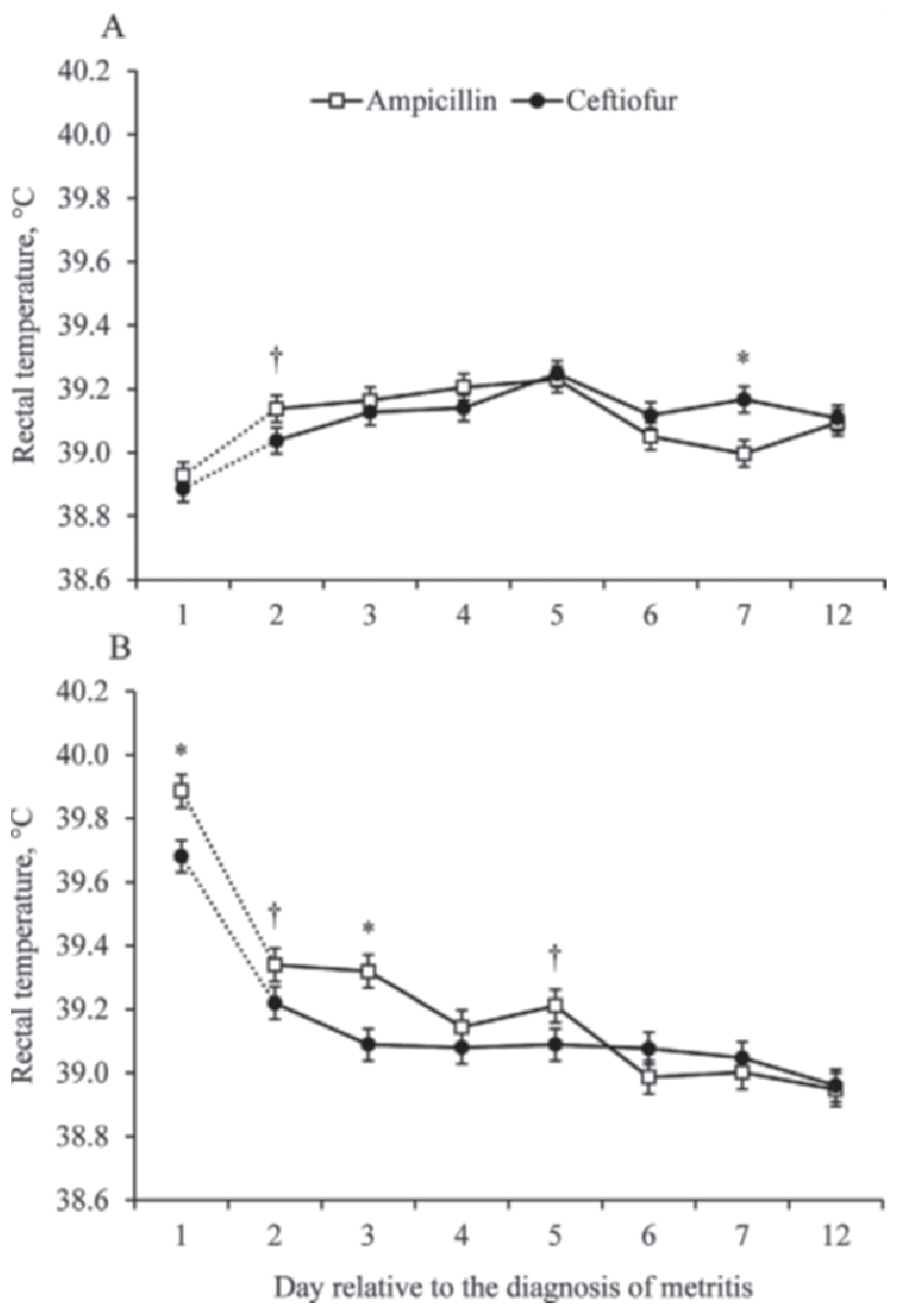

Figure 3. Rectal temperatures on d 2, 3, 4, 5, 6, 7, and 12 relative to the diagnosis of metritis according to treatment and stratified by type of metritis ( $\mathrm{A}=$ fetid discharge; $\mathrm{B}=$ puerperal metritis). Day 1 was the day of diagnosis of metritis and used as a covariate for analysis. Cows diagnosed with metritis were blocked by parity and type of metritis (fetid discharge vs. puerperal metritis) and, within each block, assigned randomly to receive $11 \mathrm{mg} / \mathrm{kg}$ of ampicillin or $2.2 \mathrm{mg} / \mathrm{kg}$ of ceftiofur once daily for $5 \mathrm{~d}$. Metritis based on fetid discharge was defined as vaginal discharge (VD) that was watery, reddish or brownish in color, foul smelling (VD score $=5$ ), and with a rectal temperature (RT) $<39.5^{\circ} \mathrm{C}$. Puerperal metritis was defined as a VD score 5 and $\mathrm{RT} \geq 39.5^{\circ} \mathrm{C}$. The mean RT for cows receiving ampicillin and ceftiofur were, respectively, $39.04 \pm 0.03$ and $39.02 \pm 0.03$ in panel A and 39.31 \pm 0.03 and $39.22 \pm 0.03$ in panel B. Effects were noted for treatment $(P=0.22)$, type of metritis $(P<0.001)$, day $(P<0.001)$, interactions between treatment and type of metritis $(P=0.20)$, treatment and day $(P<0.001)$, and treatment and type of metritis and day $(P<0.01)$. Within a day, different symbols denote statistical difference between treatments $(* P \leq 0.05 ; \dagger P<0.10)$. 
proportion of cows with fever decreased $(P<0.001)$ over time, from $23.8 \%$ on study d 2 to $17.0 \%$ on study d 12. No interactions between treatment and type of metritis, parity, or day in the study were observed for the proportion of cows with fever in the first $12 \mathrm{~d}$ after the start of treatments.

\section{Metritis Cure Based on Vaginal Discharge Score $<5$}

Of the 528 cows randomly assigned to treatments, 526 were evaluated for cure on d 5,525 were evaluated on d 7, and 517 on d 12. Before study d 12, 11 (5 ampicillin and 6 ceftiofur) cows were not evaluated for vaginal discharge score because they were culled ( $1 \mathrm{am}$ picillin, 2 ceftiofur) or died (4 ampicillin, 4 ceftiofur).

Clinical cures based on a vaginal discharge score $<5$ were greater for ampicillin than ceftiofur on d $5(P$ $<0.01)$ and $7(P=0.02)$ of the study; however, no difference $(P=0.40)$ in cure rate on $\mathrm{d} 12$ was detected between treatments (Figure 4A). Cows with puerperal metritis had reduced cure on d $5(P<0.001), 7(P<$ $0.001)$, and $12(P<0.01)$ compared with cows with fetid discharge (Figure 5A). Nevertheless, no interaction between treatment and type of metritis was observed for cure based on vaginal discharge $<5$ on d 5 , 7 , and 12 after initiation of treatments. Multiparous cows had increased $(P<0.01)$ cure than primiparous on study d 5 , but not on d 7 and 12 (Figure 6A). Cows with calving-related disorders had reduced $(P=0.02)$ cure on d 5 and tended $(P=0.07)$ to have reduced cure on $\mathrm{d} 7$ compared with cows with normal calving (Figure 7A). However, on d 12 of the study, the cure of metritis was the same for cows with and without calving-related disorders. No interactions were observed between treatment and type of metritis, parity, or calving-related disorders for cure based on vaginal discharge score $<5$ on d 5,7 , and 12 of the study.

\section{Metritis Cure Based on Vaginal Discharge Score $<5$ and Rectal Temperature $<39.5^{\circ} \mathrm{C}$}

When cure rates were analyzed according to a vaginal discharge score $<5$ and concurrent rectal temperature $<39.5^{\circ} \mathrm{C}$, cows treated with ampicillin had increased $(P<0.01)$ cure of metritis on $\mathrm{d} 7$ compared with cows treated with ceftiofur, but the proportion of cows with metritis cured on d $5(P=0.18)$ and $12(P=0.76)$ did not differ between treatments (Figure 4B). Cows with puerperal metritis had reduced $(P<0.01)$ clinical cure throughout the 12-d observational period compared with cows with metritis based on only on fetid discharge (Figure 5B). Multiparous cows tended $(P=$ 0.07 ) to have increased clinical cure on $\mathrm{d} 5$, but reduced clinical cure on d 12 after the initiation of treatments

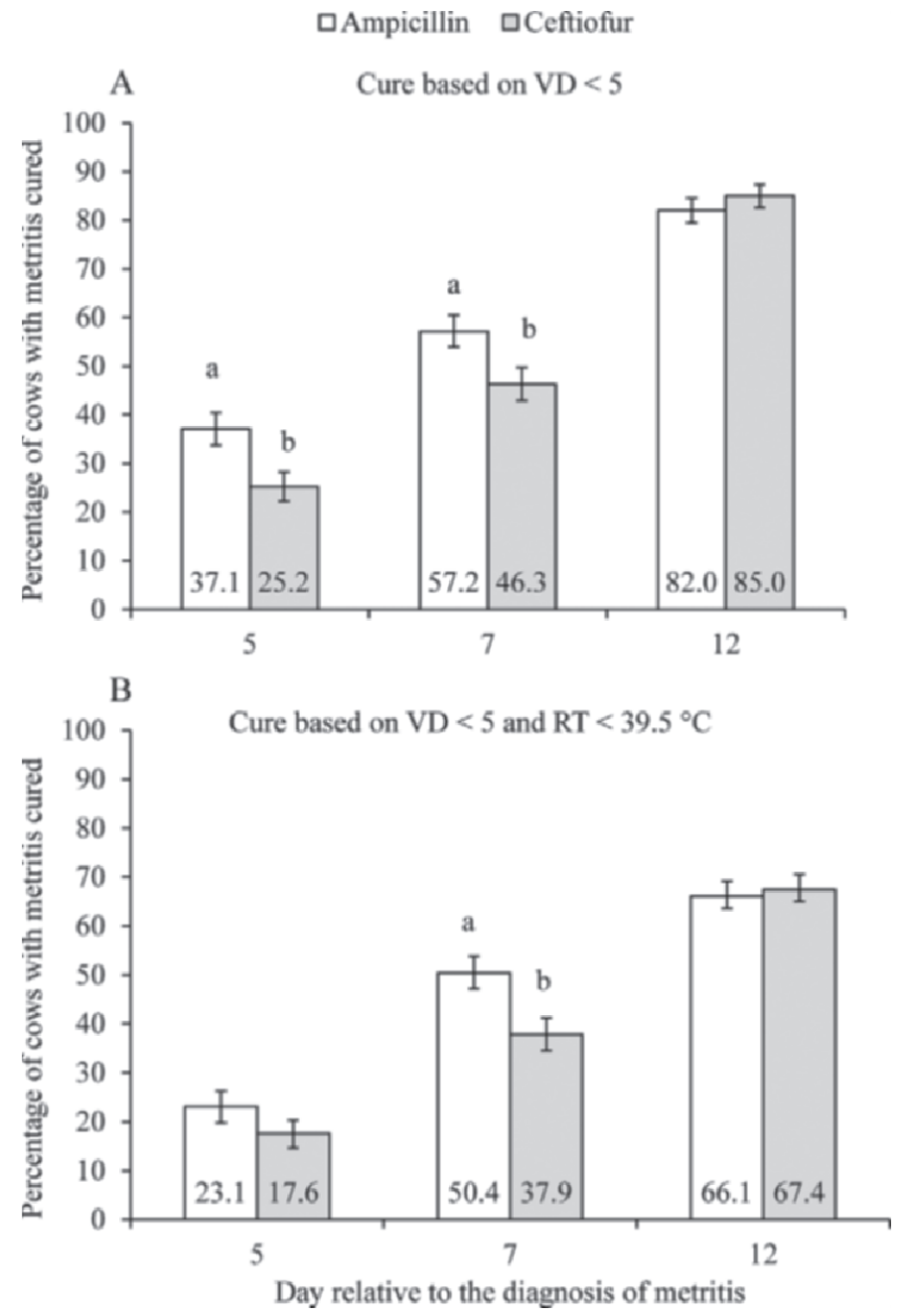

Figure 4. Adjusted proportions ( \pm SEM) of cows with metritis cured on $\mathrm{d} 5,7$, and 12 relative to the diagnosis of metritis and initiation of treatments with ampicillin or ceftiofur. Cows diagnosed with metritis were blocked by parity and type of metritis (fetid discharge vs. puerperal metritis) and, within each block, assigned randomly to receive $11 \mathrm{mg} / \mathrm{kg}$ of ampicillin or $2.2 \mathrm{mg} / \mathrm{kg}$ of ceftiofur once daily for $5 \mathrm{~d}$. Metritis based on fetid discharge was defined as vaginal discharge (VD) that was watery, reddish or brownish in color, foul smelling (VD score $=5)$, and with a rectal temperature $(\mathrm{RT})<39.5^{\circ} \mathrm{C}$. Puerperal metritis was defined as a VD score of 5 and RT $>39.5^{\circ} \mathrm{C}$. Day 1 was the day of diagnosis of metritis and first day of treatment. On panel A, cure of metritis was based on $\mathrm{VD}<5$. On panel $\mathrm{B}$, cure of metritis was based on VD $<5$ and $\mathrm{RT}<39.5^{\circ} \mathrm{C}$. Within a day, different letters $(\mathrm{a}, \mathrm{b})$ denote statistical difference $(P \leq 0.05)$ between treatments.

than primiparous cows (Figure 6B). Cow diagnosed with calving-related problems had reduced $(P=0.001)$ clinical cure on study d 5 than those with normal calving, but this difference was no longer present on study d 7 and 12 (Figure 7B). No interactions were noted between treatment and type of metritis, parity, or calving-related disorders for cure based on vaginal discharge score $<5$ and rectal temperature $<39.5^{\circ} \mathrm{C}$ on d 5,7 , and 12 of the study. 

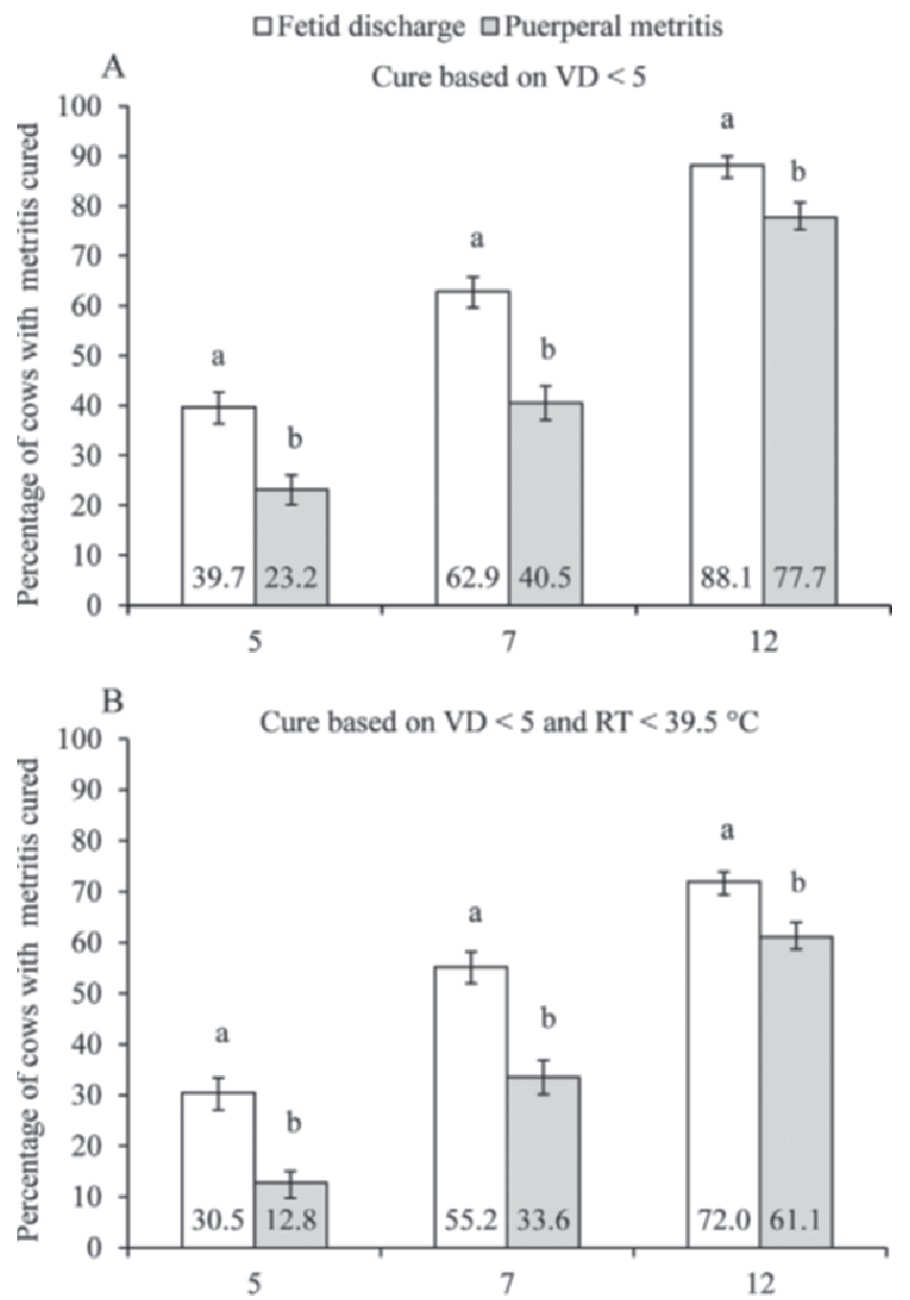

Day relative to the diagnosis of metritis

Figure 5. Adjusted proportions $( \pm$ SEM) of cows with metritis cured on $\mathrm{d} 5,7$, and 12 relative to the day of diagnosis of metritis and initiation of treatments according to initial diagnosis of fetid discharge or puerperal metritis. Cows diagnosed with metritis were blocked by parity and type of metritis (fetid discharge vs. puerperal metritis) and, within each block, assigned randomly to receive $11 \mathrm{mg} / \mathrm{kg}$ of ampicillin or $2.2 \mathrm{mg} / \mathrm{kg}$ of ceftiofur once daily for $5 \mathrm{~d}$. Metritis based on fetid discharge was defined as vaginal discharge (VD) that was watery, reddish or brownish in color, foul smelling (VD score $=5$ ), and with a rectal temperature $(\mathrm{RT})<39.5^{\circ} \mathrm{C}$. Puerperal metritis was defined as a VD score of 5 and $R T \geq 39.5^{\circ} \mathrm{C}$. Day 1 was the day of diagnosis of metritis and first day of treatment. On panel A, cure of metritis was based on $\mathrm{VD}<5$. On panel $\mathrm{B}$, cure of metritis was based on $\mathrm{VD}<5$ and $\mathrm{RT}<39.5^{\circ} \mathrm{C}$. Within a day, different letters $(\mathrm{a}, \mathrm{b})$ denote statistical difference $(P \leq 0.05)$ between treatments.

\section{Metritis Cure Based on Vaginal Discharge Score $<5$, Rectal Temperature $<39.5^{\circ} \mathrm{C}$, and No Additional Antimicrobial Therapy}

A total of 32 cows, 16 in each of the ampicillin and ceftiofur treatment groups, received additional antimicrobial therapy during the $12-\mathrm{d}$ observational period and were considered a failure of the original treatment.

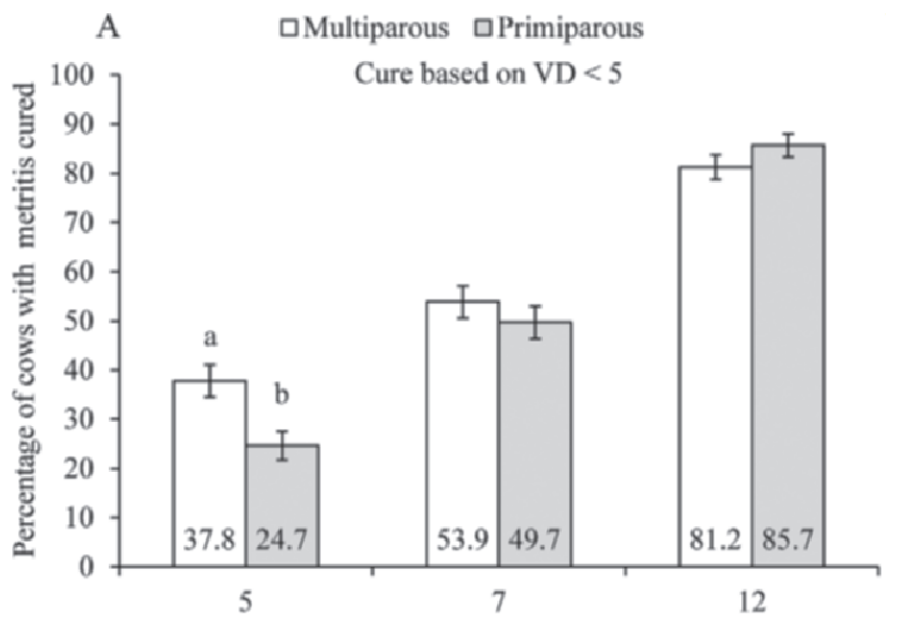

B

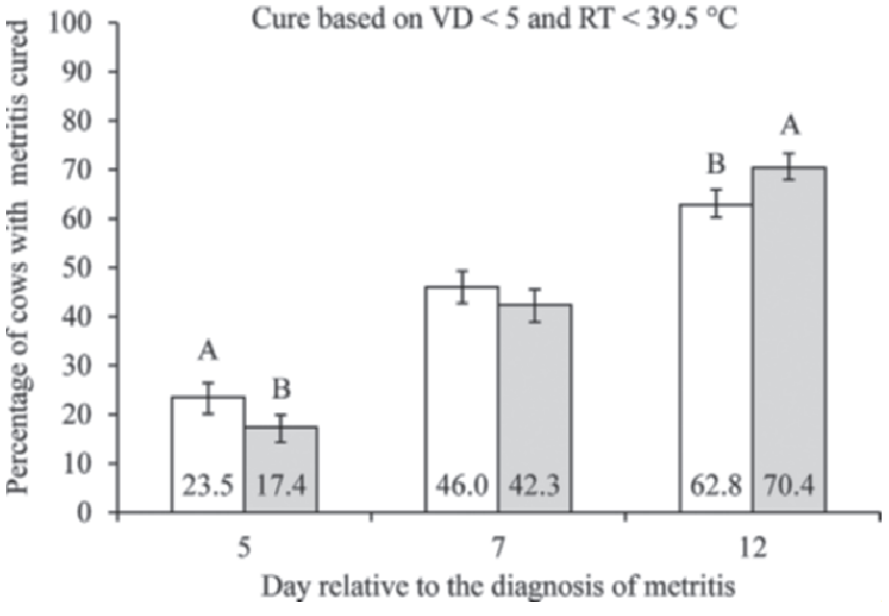

Figure 6. Adjusted proportions ( \pm SEM) of cows with metritis cured on d 5, 7, and 12 relative to the day of diagnosis of metritis and initiation of treatments according to parity. Cows diagnosed with metritis were blocked by parity and type of metritis (fetid discharge vs. puerperal metritis) and, within each block, assigned randomly to receive $11 \mathrm{mg} / \mathrm{kg}$ of ampicillin or $2.2 \mathrm{mg} / \mathrm{kg}$ of ceftiofur once daily for $5 \mathrm{~d}$. Metritis based on fetid discharge was defined as vaginal discharge (VD) that was watery, reddish or brownish in color, foul smelling (VD score $=5)$, and with a rectal temperature $(\mathrm{RT})<39.5^{\circ} \mathrm{C}$. Puerperal metritis was defined as a VD score of 5 and $\mathrm{RT} \geq 39.5^{\circ} \mathrm{C}$. Day 1 was the day of diagnosis of metritis and first day of treatment. On panel $\mathrm{A}$, cure of metritis was based on $\mathrm{VD}<5$. On panel $\mathrm{B}$, cure of metritis was based on $\mathrm{VD}<5$ and $\mathrm{RT}<39.5^{\circ} \mathrm{C}$. Within a day, different lowercase letters $(\mathrm{a}, \mathrm{b})$ denote statistical difference $(P \leq 0.05)$ between treatments; different uppercase letters $(\mathrm{A}, \mathrm{B})$ denote a tendency for statistical difference $(P \leq 0.10)$.

On d 12, the proportion of cows considered clinically cured was similar $(P=0.63)$ between ampicillin and ceftiofur (58.2 vs. $60.4 \%)$. Cows with puerperal metritis had reduced $(P=0.02)$ clinical cure than those with fetid discharge (54.0 vs. $64.3 \%$ ). Conversely, primiparous cows had a greater $(P=0.03)$ proportion of cows cured than multiparous cows $(63.9$ vs. $54.5 \%)$. Cows with calving-related disorders had similar clinical cure on d 12 compared with cows with normal calving, at an 
average of $59.2 \%$. No interactions between treatment and type of metritis, parity, or calving-related disorders were observed for cure of metritis on $\mathrm{d} 12$ based on vaginal discharge score $<5$, rectal temperature $<39.5^{\circ} \mathrm{C}$, and no additional antimicrobial therapy.

\section{PVD and Cytological Endometritis}

A total of 760 cows were evaluated for PVD on d 32 postpartum, 248 cows in the ampicillin group, 252 in the ceftiofur group, and 260 without metritis. The proportions of vaginal discharge scores 1 and 2 were, respectively, 4.4 and $40.0 \%$ for ampicillin, 3.2 and $32 . \%$ for ceftiofur, and 7.1 and $45.7 \%$ for cows without metritis. Cows receiving ampicillin had reduced $(P=$ 0.03) prevalence of PVD on d 32 postpartum compared with those treated with ceftiofur, but they were both greater $(P<0.01)$ than cows without metritis (Figure $8 \mathrm{~A})$. The benefits of ampicillin in reducing PVD were observed in cows with fetid discharge (ampicillin $=49.1$ vs. ceftiofur $=68.4 \%$ ), but not in those with puerperal metritis (ampicillin $=68.5$ vs. ceftiofur $=66.9 \%$ ). The prevalence of cytological endometritis on d 39 postpartum did not differ $(P=0.38)$ for cows with metritis treated with ampicillin or ceftiofur, but was greater $(P<0.01)$ when compared with cows without metritis (Figure 8B).

\section{Estrous Cyclicity, P/Al, and Pregnancy Loss}

Twenty-nine cows treated with ampicillin (14 sold, 7 dead, 4 with pyometra, and 4 with adhesion of the reproductive tract), 42 cows treated with ceftiofur (21 sold, 13 dead, 3 with pyometra, and 5 with adhesion of the reproductive tract), and 21 cows without metritis (16 sold, 4 dead, 1 with pyometra) did not receive the first AI or contributed to the analysis of $\mathrm{P} / \mathrm{AI}$ and pregnancy loss. Therefore, 749 cows from the initial 796 cows enrolled in the study contributed with data for resumption of estrous cyclicity and 704 cows contributed to the data for $\mathrm{P} / \mathrm{AI}$.

The percentage of estrous cyclic cows by $64 \pm 3$ DIM did not differ among treatments and averaged $75 \%$ (Table 1). A greater $(P<0.01)$ proportion of multiparous cows were cycling at 64 DIM than primiparous cows (79.1 vs. $70.9 \%)$. For cows randomly assigned to treatments, type of metritis did not influence $(P=0.91)$ resumption of estrous cyclicity and 75.5 and $75.0 \%$ of cows with fetid discharge and cows with puerperal metritis resumed ovulation by 64 DIM.

For the first postpartum AI, no difference $(P=0.17)$ in the proportion of cows inseminated following detected estrus $(65.8 \%)$ or timed AI $(34.2 \%)$ was observed among treatments. Proportions of cows inseminated at

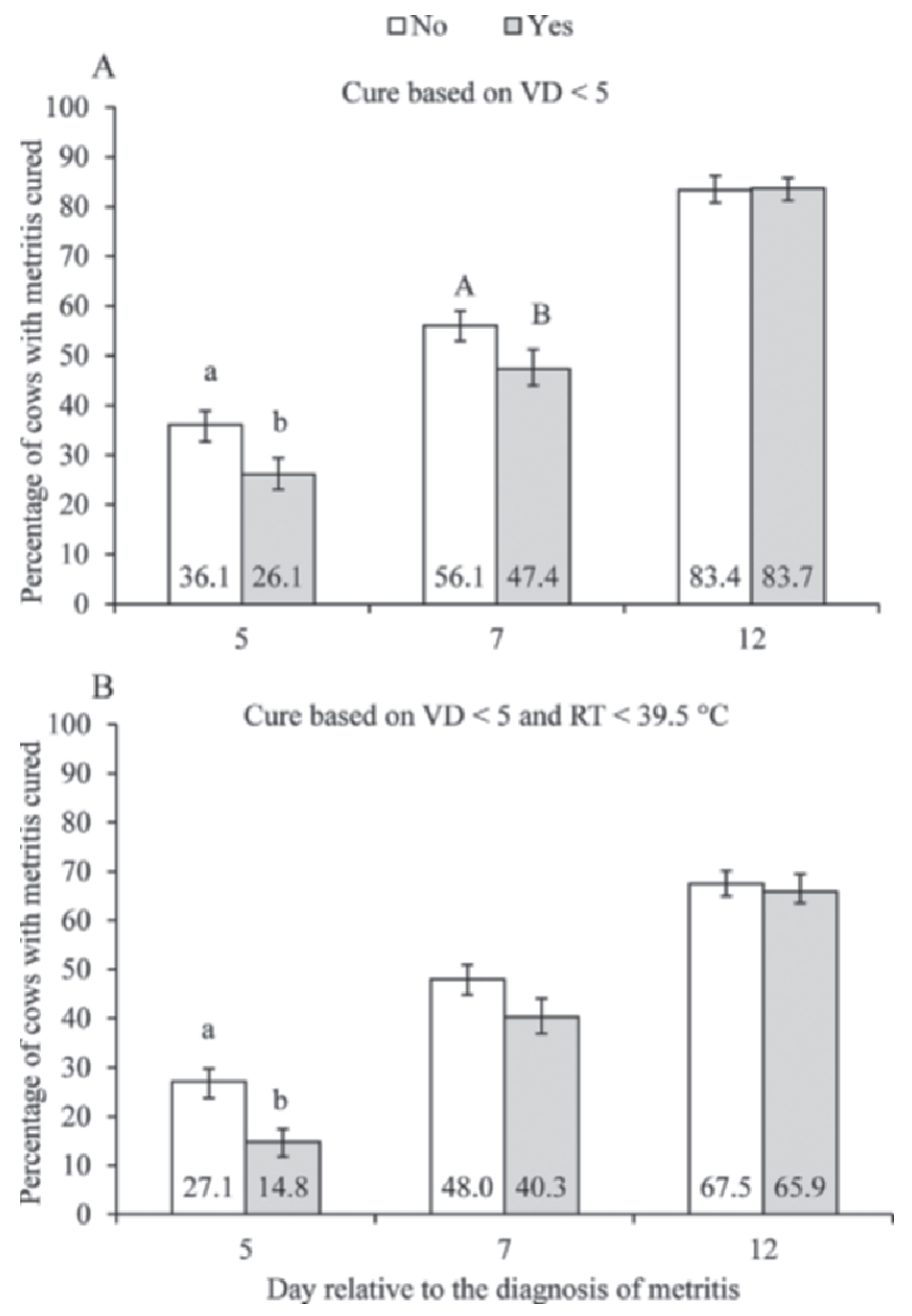

Figure 7. Adjusted proportions ( \pm SEM) of cows with metritis cured on $\mathrm{d} 5,7$, and 12 after initiation of treatments according to diagnosis of calving-related disorders (dystocia, stillbirth, twins, or retained placenta). Cows diagnosed with metritis were blocked by parity and type of metritis (fetid discharge vs. puerperal metritis) and, within each block, assigned randomly to receive $11 \mathrm{mg} / \mathrm{kg}$ of ampicillin or $2.2 \mathrm{mg} / \mathrm{kg}$ of ceftiofur once daily for $5 \mathrm{~d}$. Metritis based on fetid discharge was defined as vaginal discharge (VD) that was watery, reddish or brownish in color, foul smelling (VD score $=5$ ), and with a rectal temperature $(\mathrm{RT})<39.5^{\circ} \mathrm{C}$. Puerperal metritis was defined as a VD score of 5 and $R T \geq 39.5^{\circ} \mathrm{C}$. Day 1 was the day of diagnosis of metritis and first day of treatment. On panel A, cure of metritis was based on $\mathrm{VD}<5$. On panel $\mathrm{B}$, cure of metritis was based on $\mathrm{VD}<5$ and $\mathrm{RT}<39.5^{\circ} \mathrm{C}$. Within a day, different lowercase letters $(\mathrm{a}, \mathrm{b})$ denote statistical difference $(P \leq 0.05)$ between treatments; different uppercase letters $(\mathrm{A}, \mathrm{B})$ denote tendency for statistical difference $(P \leq 0.10)$.

detected estrus following the second $\mathrm{PGF}_{2 \alpha}$ injection postpartum were $71.1,66.7$, and $60.5 \%$ for ampicillin, ceftiofur, and cows without metritis, respectively. Pregnancy per AI on d 34 and 62 after first insemination did not differ among treatments (Table 1). For cows randomly assigned to treatments, type of metritis did not influence $(P<0.95) \mathrm{P} / \mathrm{AI}$ on d 34 or 62 after insemination. Pregnancies per AI on d 64 were 26.7 and $26.4 \%$ 

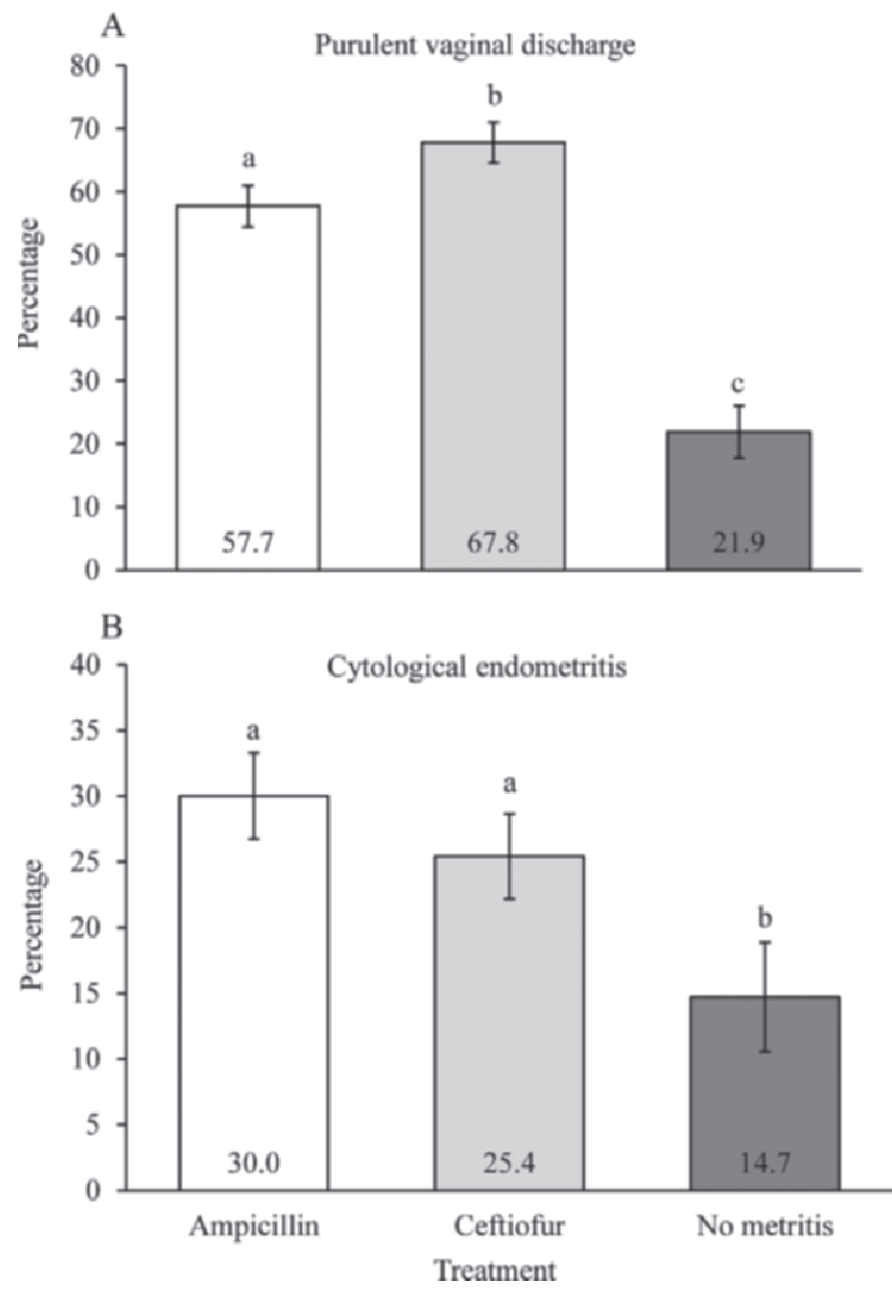

Figure 8. Adjusted proportions ( \pm SEM) of cows with purulent vaginal discharge on d $32 \pm 3$ postpartum (panel A) or with cytological endometris on $\mathrm{d} 39 \pm 3$ postpartum (panel B). Cows diagnosed with metritis were blocked by parity and type of metritis (fetid discharge vs. puerperal metritis) and, within each block, assigned randomly to receive $11 \mathrm{mg} / \mathrm{kg}$ of ampicillin or $2.2 \mathrm{mg} / \mathrm{kg}$ of ceftiofur once daily for $5 \mathrm{~d}$. Metritis based on fetid discharge was defined as vaginal discharge (VD) that was watery, reddish or brownish in color, foul smelling (VD score $=5)$, and with a rectal temperature $(\mathrm{RT})<39.5^{\circ} \mathrm{C}$. Puerperal metritis was defined as a VD score of 5 and $\mathrm{RT} \geq 39.5^{\circ} \mathrm{C}$. For panel A, effect of treatment was $P<0.001$; for panel B, effect of treatment was $P<0.001$. Within a day, different letters $(\mathrm{a}-\mathrm{c})$ denote statistical difference $(P \leq 0.05)$.

for cows with fetid discharge and cows with puerperal metritis, respectively. Similar to P/AI, pregnancy loss between 34 and $62 \mathrm{~d}$ of gestation did not differ among treatments.

\section{DISCUSSION}

Ampicillin was an efficacious alternative treatment for metritis and showed clinical efficacy similar to or better than ceftiofur. Cows with metritis treated with ampicillin trihydrate had an increased cure rate at $\mathrm{d} 5$ and 7 after metritis diagnosis than those treated with ceftiofur hydrochloride. Although the present study design does not allow for detection of spontaneous cure, it is known that a large proportion of cows diagnosed with puerperal metritis not receiving antimicrobial therapy have remission of clinical symptoms within 14 d of diagnosis (Chenault et al., 2004; McLaughlin et al., 2012). Treatment with ampicillin resulted in a greater proportion of cows clinically cured on $\mathrm{d} 7$ after initiation of treatments when the criteria for cure was either vaginal discharge $<5$ or a combination of vaginal discharge $<5$ concurrent with a rectal temperature $<39.5^{\circ} \mathrm{C}$. This benefit was observed in both cows with metritis based on fetid discharge and cows with puerperal metritis, which indicates that ampicillin cured metritis and puerperal metritis at a faster rate than ceftiofur.

The nomenclature used to define metritis and puerperal metritis has been inconsistent. Although $59.1 \%$ of the cows enrolled to receive antimicrobial treatments only had fetid uterine discharge on the day of diagnosis, more than half of those cows eventually developed fever during the subsequent days when antimicrobial therapy had already been instituted. Metritis has been defined based on the presence of fetid red-brown watery uterine discharge and delayed uterine involution, whereas puerperal metritis is defined as metritis concurrent with fever or other clinical signs of disease (Sheldon et al., 2006). Nonetheless, the evidence to support delayed uterine involution as an accurate method to detect metritis is weak, and valid diagnostic criteria are not consistently applied among studies (Sannmann et al., 2012). Most, if not all, postpartum cows will have an enlarged uterus in the first 4 to 6 DIM, when most cases of metritis are diagnosed, as observed in the current study in which the mean $( \pm \mathrm{SD})$ and median DIM at diagnosis were $5.4 \pm 1.7$ and 5.0, respectively. The fact that more than half of the cows with metritis based on fetid uterine discharge and no fever on the day of enrollment eventually developed fever during the course of antimicrobial therapy suggests that these cows developed systemic signs of disease beyond the affected uterus.

Early in the course of treatment, cows receiving ceftiofur had lower rectal temperature than those treated with ampicillin, particularly those with puerperal metritis; however, body temperature equalized quickly after therapy was initiated. The reduced body temperature for cows treated with ampicillin further indicates that clinical efficacy to cure metritis was similar to that of ceftiofur. As anticipated, cows presenting puerperal metritis, a more debilitating form of the disease, had reduced cure rates at 5,7 , and $12 \mathrm{~d}$ after diagnosis compared with cows with fetid discharge, and antimicrobial therapy with either ampicillin or ceftiofur were equally 
Table 1. Effect of treatment on estrous cyclicity, pregnancy per AI, and pregnancy loss following the first postpartum $\mathrm{AI}^{1}$

\begin{tabular}{lcccc}
\hline & \multicolumn{3}{c}{ Treatment $^{2}$} \\
\cline { 2 - 3 } Item & Ampicillin & Ceftiofur & Without metritis & $P$-value \\
\hline Estrous cyclicity $^{3}$ & $74.8(184 / 245)$ & $75.9(185 / 246)$ & $75.1(198 / 258)$ & 0.96 \\
Pregnancy at first AI $_{\text {d 34 }}$ & $28.9(61 / 230)$ & $29.1(70 / 227)$ & $32.0(84 / 215)$ & 0.87 \\
d 62 & $27.9(58 / 230)$ & $28.3(65 / 227)$ & $30.5(76 / 215)$ & 0.91 \\
Pregnancy loss & $5.8(3 / 61)$ & $6.1(5 / 70)$ & $11.3(8 / 84)$ & 0.52 \\
\hline
\end{tabular}

${ }^{1}$ Presented as adjusted means (no./no.).

${ }^{2}$ Cows with metritis were blocked by type of metritis (fetid discharge or puerperal metritis) and assigned randomly to receive $11 \mathrm{mg} / \mathrm{kg}$ of ampicillin or $2.2 \mathrm{mg} / \mathrm{kg}$ of ceftiofur once daily for $5 \mathrm{~d}$. Cows without metritis were randomly selected at $12 \mathrm{~d}$ postpartum based on the day of calving and parity.

${ }^{3}$ Estrous cyclicity by $64 \mathrm{~d}$ postpartum was based on the presence of a corpus luteum in 1 of the ovaries in at least 1 of the 2 ultrasound examinations on d $50 \pm 3$ and $64 \pm 3$ postpartum.

efficacious at resolving puerperal metritis within the first $12 \mathrm{~d}$ after diagnosis. Unfortunately, because of well-being concerns and potential implications to subsequent performance, the study design did not allow determining the efficacy of either therapy compared with an untreated group.

Ampicillin and ceftiofur are both $\beta$-lactam antibiotics that bind irreversibly to bacterial enzyme dd-transpeptidase, blocking the formation crosslinks between this enzyme and peptidoglycan, which compromises the formation of rigid cell wall synthesis in binary fission, thereby ultimately leading to cell lysis (Prescott and Baggott, 1993; Chambers, 2007). Ampicillin is classified as amino-penicillin because of the presence of an amino group as part of its core. This amino group is critical for ampicillin to penetrate the outer membrane of gram-negative bacteria, which gives the drug its broad spectrum by killing both gram-positive and -negative bacteria (Chambers, 2007). Ceftiofur also has effectiveness against gram-positive and -negative bacteria and is resistant to $\beta$-lactamase, therefore preventing the action of these enzymes on the degradation of the $\beta$-lactam ring, which inactivates many antibiotics of this class (Collatz et al., 1990). Ampicillin and ceftiofur are both effective against gram-negative bacteria, such as E. coli (Lehtolainen et al., 2003; Sheldon et al., 2004).

Recently, bacteria that express specific virulence factors were associated with increased risk of development of uterine diseases (Bicalho et al., 2012). Escherichia coli expressing the adhesin type I fimbriae fim $H$ identified in the uterus of cows in the first $3 \mathrm{~d}$ postpartum was associated with development of metritis and endometritis. Fusobacterium necrophorum expressing the leukotoxin/hemolysin $l k t A$ in the first $3 \mathrm{~d}$ or between $\mathrm{d}$ 8 and 12 postpartum was associated with endometritis. Trueperella pyogenes expressing the type I fimbriae adhesin fim $A$ and the pyolysin plo between 8 and 10 or 34 and 36 d postpartum was associated with endome- tritis (Bicalho et al., 2012). It has been suggested that the presence of $E$. coli expressing the virulence factor fim $H$ in the uterus of cows in the first few days postpartum paves the way for the other bacterial infection coordinating the initial process of tissue damage and development of uterine diseases (Bicalho et al., 2012). Efficacy against E. coli, particularly those expressing the virulence factor fimH, might limit the extent of pathogenic bacteria colonization of the uterus and reduce the intensity of disease.

It is interesting to note that $53.2 \%$ of the cows with metritis, based on fetid discharge on the day of study enrollment, developed fever after the antimicrobial therapy had been initiated. Furthermore, $30.6 \%$ of the cows metritis based on fetid discharge had fever on any given day after initiating treatment with either ampicillin or ceftiofur. These cows were not diagnosed with fever on the first day of treatment, but developed rectal temperature $\geq 39.5^{\circ} \mathrm{C}$ despite treatment with antimicrobials. In general, treating cows suffering from puerperal metritis with antimicrobials reduces body temperature (Chenault et al., 2004; McLaughlin et al., 2012). Interestingly, the decline in body temperature is also observed in metritic cows that remain untreated (Chenault et al., 2004; McLaughlin et al., 2012), indicating normal resolution of the disease by the cow's immune system. Nevertheless, it is suggested that that a portion of the cows with fetid discharge that are treated become worse or do not respond to antibiotics. The design of the current study allowed us to demonstrate that cure of metritis is reduced when cows have the disease concurrent with fever. Nevertheless, the design does not allow us to evaluate cure of cows diagnosed with metritis based on fetid discharge differ between those receiving antimicrobials, such as ampicillin or ceftiofur, or if left untreated, as has been evaluated by others for puerperal metritis (Chenault et al., 2004; McLaughlin et al., 2012). 
Administration of ceftiofur at the dose of $1.0 \mathrm{mg} /$ $\mathrm{kg}$, which is less than the $2.2 \mathrm{mg} / \mathrm{kg}$ prescribed dose in United States, resulted in concentrations of ceftiofur derivatives above those capable of inhibiting the growth of utero-pathogenic bacteria (Sheldon et al., 2004; Drillich et al., 2006). The concentration of ampicillin in uterine tissue after systemic administration is undefined, thus it remains unknown if the dose used would lead to optimum to concentrations of ampicillin in the uterine tissues. Conversely, when ampicillin is administered to cattle, concentrations increase immediately and reach approximately $0.9 \mu \mathrm{g} / \mathrm{mL}$ in plasma, followed by a decline to values of approximately 0.3 and $0.4 \mu \mathrm{g} / \mathrm{mL}$ for the next $24 \mathrm{~h}$, which suggests potential efficacy against major pathogens (Gehring et al., 2005). Therefore, it is reasonable to speculate that the similar clinical efficacy of ampicillin and ceftiofur is likely related to their ability to maintain concentrations of antibiotics sufficient to inhibit the growth of the major pathogens that cause uterine disease.

Many studies evaluating the clinical efficacy of antibiotics for therapy of puerperal metritis evaluated the remission of the disease with reduction in fever and improvements in uterine discharge score (Chenault et al., 2004; McLaughlin et al., 2012). However, because of extensive spontaneous cure, even in cows with puerperal metritis (Chenault et al., 2004; McLaughlin et al., 2012), it is critical that the evaluation of therapy goes beyond clinical cure. In fact, proper treatment of metritis can influence milk yield and reproductive performance (Goshen and Shpigel, 2006). Despite a faster cure and a small reduction in the prevalence of PVD, treatment with ampicillin resulted in similar prevalence of estrous cyclic cows and P/AI to the first postpartum insemination compared with cows treated with ceftiofur. It has been reported consistently in the literature that PVD has detrimental effects on fertility (Gilbert et al., 2005; Dubuc et al., 2011), and one would anticipate that reductions in the prevalence of PVD and cytological endometritis would benefit fertility at first AI. However, it is possible that the changes in prevalence of PVD and cytological endometritis caused by metritis were insufficient to affect fertility, particularly when intensive therapy is applied. All cows in the current study were subjected to a presynchronized timedAI protocol; however, evidence from previous studies suggests that it is unlikely that hormonal treatments, particularly the use of $\mathrm{PGF}_{2 \alpha}$, to benefit uterine health would influence P/AI (Dubuc et al., 2011; Lima et al., 2013). Therefore, the improved cure rates and rectal temperature on $\mathrm{d} 7$ after metritis diagnosis and reduced prevalence of PVD identified in cows treated with ampicillin in comparison with ceftiofur did not improve reproductive performance in the current study. Results from the current study suggest that the antimicrobials used had similar efficacy to reestablish fertility in cows with metritis.

The lack of difference in P/AI between cows without metritis and those with metritis treated with ampicillin or ceftiofur were surprising considering the wellknown negative associations between uterine diseases and subsequent fertility (Dubuc et al., 2011; Lima et al., 2013). It is unclear why cows with metritis had similar P/AI and risk of pregnancy loss compared with cows without metritis. It is possible that an early diagnosis and prompt therapy might have minimized the negative effect of metritis on fertility. Goshen and Shpigel (2006) allocated cows diagnosed with metritis to receive 4 treatments with $5 \mathrm{~g}$ of chlortetracycline as intrauterine boluses over the course of 2 wk or to remain as untreated controls. The $\mathrm{P} / \mathrm{AI}$ at first postpartum insemination were $38.3,42.5$, and $18 \%$ in cows without metritis, cows with metritis treated with chlortetracycline, and cows with metritis that remained as untreated controls, respectively. Rabaglino et al. (2009) evaluated records from 2,300 cows from 2 farms in which an intensive postpartum health monitoring program was implemented, and cows diagnosed with metritis received prompt antimicrobial therapy as combinations of systemic ceftiofur with or without intrauterine bolus of tetracycline. All cows were subjected to a presynchronized timed-AI protocol and were inseminated at 67 DIM. No difference was observed for P/AI at the first postpartum timed AI when cows without metritis $(33.3 \%)$ were compared with cows diagnosed and treated for metritis (29.9\%). It is conceivable that daily diagnosis and diligent therapy with proper duration might have offset some of the negative effects of metritis on fertility of dairy cows. Although we can only speculate, it is possible that proper compliance and adequate duration of antimicrobial therapy might reestablish uterine health such that P/AI is not compromised. Nonetheless, further investigation is needed to establish treatment schemes that result in high clinical cure and reestablishment of fertility similar to that of unaffected cows.

\section{CONCLUSIONS}

Ampicillin was an efficacious alternative therapy for metritis, resulting in faster cure rates than ceftiofur; however, by d 12 after the diagnosis of metritis, no differences between treatments were observed. Ampicillin reduced the prevalence of cows with PVD on d 32 postpartum compared with cows receiving ceftiofur, but treatment did not affect the prevalence of cytological endometritis in cows previously diagnosed with metritis. Similarly, treatment did not affect the 
resumption of estrous cyclicity by $64 \mathrm{~d}$ postpartum, $\mathrm{P}$ / $\mathrm{AI}$ at first AI, and the risk of pregnancy loss. Although cows without metritis had reduced prevalence of PVD and cytological endometritis compared with metritic cows, estrous cyclicity and P/AI did not differ between those without metritis and metritic cows treated with ampicillin or ceftiofur. More than half of the cows with metritis based on fetid uterine discharge and no fever on the day of enrollment eventually developed fever despite antimicrobial treatment. Type of metritis was an indicator of severity of the disease, and cows with puerperal metritis had poorer cure rates than those with metritis based on fetid uterine discharge. Nevertheless, type of metritis did not influence subsequent estrous cyclicity, P/AI, or risk of pregnancy loss.

\section{ACKNOWLEDGMENTS}

The authors thank the owner and staff of Alliance Dairies (Trenton, FL) for the use of their cows and facilities. Our appreciation is extended to Nilo Francisco and Hernan Herrera of Alliance Dairies. The assistance of Leandro Greco, Eduardo Ribeiro, Leticia Sinedino, Pedro Monteiro Jr., Tony Bruinje, and Javier Juarez from the University of Florida, and from Douglas Ensley and Mark van der List from Boehringer Ingelheim Vetmedica during the conduct of this experiment is greatly appreciated. Funding for this study was provided by a grant from Boehringer Ingelheim Vetmedica (St. Joseph, MO).

\section{REFERENCES}

Bicalho, M. L. S., V. S. Machado, G. Oikonomou, R. O. Gilbert, and R. C. Bicalho. 2012. Association between virulence factors of Escherichia coli, Fusobacterium necrophorum, and Arcanobacterium pyogenes and uterine diseases of dairy cows. Vet. Microbiol. 157:125-131.

Bicalho, R. C., K. N. Galvão, C. L. Guard, and J. E. P. Santos. 2008. Optimizing the accuracy of detecting a functional corpus luteum in dairy cows. Theriogenology 70:199-207.

Burrows, G. E., R. J. Morton, and W. H. Fales. 1993. Microdilution antimicrobial susceptibilities of selected gram-negative veterinary bacterial isolates. J. Vet. Diagn. Invest. 5:541-547.

Chambers, H. R. 2007. Beta-lactam and other cell wall and membraneactive antibiotics. Pages 726-744 in Basic and Clinical Pharmacology, 10th ed. B.G. Katzung, ed. McGraw Hill Medical, New York, NY.

Chapinal, N., M. Carson, T. F. Duffield, M. Capel, S. Godden, M. Overton, J. E. P. Santos, and S. J. LeBlanc. 2011. The association of serum metabolites with clinical disease during the transition period. J. Dairy Sci. 94:4897-4903.

Chenault, J. R., J. F. McAllister, T. Chester, K. J. Dame, F. M. Kausche, and E. J. Robb. 2004. Efficacy of ceftiofur hydrochloride administered parenterally for the treatment of acute postpartum metritis in dairy cows. J. Am. Vet. Med. Assoc. 224:1634-1639.

Collatz, E., R. Labia, and R. Gutmann. 1990. Molecular evolution of ubiquitous beta-lactamases towards extended-spectrum enzymes active against newer beta-lactam antibiotics. Mol. Microbiol. 4:1615-1620.
Drillich, M., S. Arlt, S. Kersting, A. A. Bergwerff, P. Scherpenisse, and W. Heuwieser. 2006. Ceftiofur derivatives in serum, uterine tissues, cotyledons, and lochia after fetal membrane retention. J. Dairy Sci. 89:3431-3438.

Drillich, M., O. Beetz, A. Pfutzner, M. Sabin, H. J. Sabin, P. Kutzer, H. Nattermann, and W. Heuwieser. 2001. Evaluation of a systemic antibiotic treatment of toxic puerperal metritis in dairy cows. J. Dairy Sci. 84:2010-2017.

Dubuc, J., T. F. Duffield, K. E. Leslie, J. S. Walton, and S. J. LeBlanc. 2010. Definitions and diagnosis of postpartum endometritis in dairy cows. J. Dairy Sci. 93:5225-5233.

Dubuc, J., T. F. Duffield, K. E. Leslie, J. S. Walton, and S. J. LeBlanc. 2011. Randomized clinical trial of antibiotic and prostaglandin treatments for uterine health and reproductive performance in dairy cows. J. Dairy Sci. 94:1325-1338.

Elanco Animal Health. 2009. The 5-point body condition scoring system. Bulletin AI 10752. Elanco Animal Health, Greenfield, IN.

FDA (Food and Drug Administration). 1998. Center for Veterinary Medicine: Approved Animal Drug Products. Accessed Jul. 11, 2013. http://www.accessdata.fda.gov/scripts/animaldrugsatfda/ details.cfm?dn=200-180.

Ferguson, J. D., D. T. Galligan, and N. Thomsen. 1994. Principal descriptors of body condition score in Holstein dairy cattle. J. Dairy Sci. $77: 2695-2703$.

Galvão, K. N., L. F. Greco, J. M. Vilela, M. F. Sá Filho, and J. E. P. Santos. 2009. Effect of intrauterine infusion of ceftiofur on uterine health and fertility in dairy cows. J. Dairy Sci. 92:1532-1542.

Gehring, R., D. van der Merwe, A. N. Pierce, R. E. Baynes, A. L. Craigmill, and J. E. Riviere. 2005. Multivariate meta-analysis of pharmacokinetic studies of ampicillin trihydrate in cattle. Am. J. Vet. Res. 66:108-112.

Gilbert, R. O., S. T. Shin, C. L. Guard, H. N. Erb, and M. Frajblat. 2005. Incidence of endometritis and its effects on reproductive performance of dairy cows. Theriogenology 64:1879-1888.

Goshen, T., and N. Y. Shpigel. 2006. Evaluation of intrauterine antibiotic treatment of clinical metritis and retained fetal membranes in dairy cows. Theriogenology 66:2210-2218.

Griffin, J. F. T., P. J. Hartigan, and W. R. Nunn. 1974. Non-specific uterine infection and bovine fertility. I. Infection patterns and endometritis during the first seven weeks post-partum. Theriogenology 1:91-106.

Jiang, X., H. Yang, B. Dettman, and M. P. Doyle. 2006. Analysis of fecal microbial flora for antibiotic resistance in ceftiofur-treated calves. Foodborne Pathog. Dis. 3:355-365.

Lehtolainen, T., A. Shwimmer, N. Y. Shpigel, T. Honkanen-Buzalski, and S. Pyorala. 2003. In vitro antimicrobial susceptibility of Escherichia coli isolates from clinical bovine mastitis in Finland and Israel. J. Dairy Sci. 86:3927-3932.

Lima, F. S., R. S. Bisinotto, E. S. Ribeiro, L. F. Greco, H. Ayres, M. G. Favoreto, M. R. Carvalho, K. N. Galvão, and J. E. P. Santos. 2013. Effects of one or two treatments with prostaglandin $F_{2 \alpha}$ on subclinical endometritis and fertility in lactating dairy cows inseminated by timed AI. J. Dairy Sci. 96:6480-6488.

Malinowski, E., H. Lassa, H. Markiewicz, M. Kaptur, M. Nadolny, W. Niewitecki, and J. Zietara. 2011. Sensitivity to antibiotics of $A r$ canobacterium pyogenes and Escherichia coli from the uteri of cows with metritis/endometritis. Vet. J. 187:234-238.

Martinez, N., C. A. Risco, F.S. Lima, R. S. Bisinotto, L. F. Greco, E. S. Ribeiro, F. Maunsell, K. N. Galvão, and J. E. P. Santos. 2012. Evaluation of peripartal calcium status, energetic profile and neutrophil function in dairy cows at low or high risk of developing uterine disease. J. Dairy Sci. 95:7158-7172.

McLaughlin, C. L., E. Stanisiewski, M. J. Lucas, C. P. Cornell, J. Watkins, L. Bryson, J. K. S. Tena, J. Hallberg, and J. R. Chenault. 2012. Evaluation of two doses of ceftiofur crystalline free acid sterile suspension for treatment of metritis in lactation dairy cows. J. Dairy Sci. 95:4363-4371.

Noakes, D. E., D. Till, and G. R. Smith. 1989. Bovine uterine flora postpartum: A comparison of swabbing and biopsy. Vet. Rec. 124:563-564. 
NRC. 2001. Nutrient Requirements of Dairy Cattle. 7th rev. ed., Natl. Acad. Sci. Washington, DC.

Prescott, J. F., and J. E. Baggott. 1993. Beta-lactam antibiotics: Penam penicillins. Pages 74-97 in Antimicrobial Therapy in Veterinary Medicine. 2nd ed. J.F. Prescott and J.D. Baggott, ed. Iowa State University Press, Ames.

Rabaglino, M. B., J. E. P. Santos, C. Fuentes, and C. A. Risco. 2009 Milk production and reproductive performance in postpartum dairy cows diagnosed and treated for metritis using a health monitoring program. Page 216 in Proc. 42nd Conf. Am. Assoc. Bov. Pract. American Association of Bovine Practitioners, Omaha, NE.

Sannmann, I., S. Arlt, and W. Heuwieser. 2012. A critical evaluation of diagnostics methods used to identify dairy cows with acute postpartum metritis in the current literature. J. Dairy Res. 79:436444.

Santos, J. E. P., R. S. Bisinotto, E. S. Ribeiro, F. S. Lima, L. F. Greco, C. R. Staples, and W. W. Thatcher. 2010. Applying nutrition and physiology to improve reproduction in dairy cattle. Soc. Reprod. Fertil. Suppl. 67:387-403.
Sheldon, I. M., M. Bushnell, J. Montgomery, and A. N. Rycroft. 2004. Minimum inhibitory concentrations of some antimicrobial drugs against bacteria causing uterine infections in cattle. Vet. Rec. 155:383-387.

Sheldon, I. M., G. S. Lewis, S. LeBlanc, and R. O. Gilbert. 2006. Defining postpartum uterine disease in cattle. Theriogenology 65:1516-1530.

Sheldon, I. M., D. E. Noakes, A. N. Rycroft, D. U. Pfeiffer, and H. Dobson. 2002. Influence of uterine bacterial contamination after parturition on ovarian dominant follicle selection and follicle growth and function in cattle. Reproduction 123:837-845.

Simon, P. C. 1977. Susceptibility of Fusobacterium necrophorum to antimicrobials. Part I: As determined by the disc method. Can. J. Comp. Med. 41:166-168.

Tragesser, L. A., T. E. Wittum, J. A. Funk, P. L. Winokur, and P. J. Rajala-Schultz. 2006. Association between ceftiofur use and isolation of Escherichia coli with reduced susceptibility to ceftriaxone from fecal samples of dairy cows. Am. J. Vet. Res. 67:1696-1700. 